\title{
Posterior chamber collagen copolymer phakic intraocular lenses to correct myopia: Five-year follow-up
}

\author{
José F. Alfonso, MD, PhD, Begoña Baamonde, MD, PhD, Luis Fernández-Vega, MD, PhD, \\ Paulo Fernandes, OD, Jose M. González-Méijome, PhD, Robert Montés-Micó, PhD
}

PURPOSE: To evaluate the long-term safety and efficacy of posterior chamber collagen copolymer phakic intraocular lens (pIOL) implantation to correct myopia.

SETTING: Fernández-Vega Ophthalmological Institute, Oviedo, Spain.

DESIGN: Cohort study.

METHODS: Uncorrected (UDVA) and corrected (CDVA) distance visual acuities, refraction, pIOL vault, endothelial cell loss, and adverse events were evaluated for 5 years after implantation of the Visian Implantable Collamer Lens pIOL for moderate to high myopia.

RESULTS: The mean spherical equivalent (188 eyes) decreased from -11.17 diopters (D) \pm 3.40 (SD) preoperatively to $-0.88 \pm 0.72 \mathrm{D} 5$ years postoperatively. The mean change in refraction from 1 month to 5 years was $-0.65 \pm 0.65 \mathrm{D}$. The mean UDVA and CDVA (Snellen decimal) were $0.69 \pm$ 0.26 and $0.83 \pm 0.15$, respectively. The mean safety and efficacy indices were $1.27 \pm 0.33$ and $0.89 \pm 0.35$, respectively. No eye lost more than 2 lines of visual acuity; $70 \%$ achieved 0.80 or better CDVA. Three eyes (1.6\%) developed late anterior subcapsular cataract that was clinically significant in 1 case, leading to pIOL removal and phacoemulsification. Of the 3 eyes (1.6\%) with a mild transient increase in intraocular pressure (up to $27 \mathrm{~mm} \mathrm{Hg}$ ), none required a second surgical procedure or prolonged topical medication. The total endothelial cell loss (considered cumulatively at consecutive intervals through 5 years) was $7.7 \%$. There was a tendency toward decreased pIOL vault decrease over time. No vision-threatening complications occurred.

CONCLUSION: Implantation of the collagen copolymer pIOL for moderate to high myopia was safe and effective and provided long-term predictable, stable refractive results.

Financial Disclosure: No author has a financial or proprietary interest in any material or method mentioned.

J Cataract Refract Surg 2011; 37:873-880 @ 2011 ASCRS and ESCRS

Today, phakic intraocular lenses (pIOLs) are usually implanted as an alternative treatment to correct ametropia of various refractive ranges. An evolving technique in the field of refractive surgery, pIOL implantation has several advantages, including fast visual recovery, excellent refractive accuracy and stability, improved visual acuity, preservation of accommodation, and reversibility.

At present, the Visian Implantable Collamer Lens pIOL (Staar Surgical Co.) is the only posterior chamber pIOL approved by the United States Food and Drug Administration (FDA) for the treatment of moderate to severe myopia. This pIOL is of a foldable collagen copolymer material and is designed to be placed in the posterior chamber, behind the iris, with a haptic zone resting on the ciliary sulcus. Several studies report its effectiveness in correcting myopia, ${ }^{1-5}$ hyperopia, ${ }^{6,7}$ and astigmatism ${ }^{8-10}$ or in patients who may not be appropriate candidates for corneal reshaping procedures. ${ }^{11-14}$ However, in addition to the risks of any intraocular surgery, ${ }^{15}$ the main concerns with pIOL implantation relate to its long-term safety, including long-term endothelial cell loss, ${ }^{16,17}$ pigmentary glaucoma, ${ }^{18}$ pupillary block, ${ }^{19,20}$ and cataract formation. ${ }^{21}$ Although studies of pIOL implantation report acceptable complication and visual acuity loss rates, few studies have spanned more than 3 years to observe the long-term clinical and refractive 
outcomes. ${ }^{22,23}$ Long-term potential problems cannot be dismissed because the risk for them may increase with time. The aim of the present study was to evaluate the long-term (up to 5 years) clinical and refractive outcomes of pIOL implantation to correct moderate to high myopia.

\section{PATIENTS AND METHODS}

This retrospective observational study included the medical records of patients who had implantation of a Visian Implantable Collamer Lens pIOL for myopia correction at Fernández-Vega Ophthalmological Institute, Oviedo, Spain, between December 2001 and January 2007 and regularly returned for evaluations for at least 3 years postoperatively. At the time of the surgery, all patients were fully informed of the details and possible risks of the surgical procedure. Written informed consent was obtained from all patients before surgery in accordance with the Declaration of Helsinki, and an institutional review board approved the study.

The inclusion criteria for pIOL implantation were a corrected distance visual acuity (CDVA) of 20/50 or better, stable refraction, and a clear central cornea. The exclusion criteria included age younger than 22 years, anterior chamber depth (ACD) less than $2.8 \mathrm{~mm}$, endothelial cell density (ECD) less than 2000 cells $/ \mathrm{mm}^{2}$, cataract, history of glaucoma or retinal detachment, macular degeneration or retinopathy, neuro-ophthalmic disease, and a history of ocular inflammation.

Before pIOL implantation, patients had a complete ophthalmologic examination including manifest and cycloplegic refractions, keratometry, corneal topography and pachymetry (Orbscan II, Bausch \& Lomb), ECD (SP 3000P, Topcon Europe Medical), slitlamp examination, Goldmann applanation tonometry, and binocular indirect ophthalmoscopy through dilated pupils. Cell counts were performed in a semiautomatic manner by the same technician. After automatic cell detection by the instrument, the technician corrected the edges of cells that had not been identified by the fully automatic image analysis. This ensured higher reliability of

Submitted: August 31, 2010.

Final revision submitted: October 21, 2010.

Accepted: November 3, 2010.

From Fernández-Vega Ophthalmological Institute (Alfonso, Baamonde, Fernández-Vega) and the Surgery Department (Alfonso, Baamonde, Fernández-Vega), School of Medicine, University of Oviedo, Oviedo, and the Optics Department, Faculty of Physics (Montés-Micó), University of Valencia, Valencia, Spain; the Clinical and Experimental Optometry Research Laboratory (Fernandes, González-Méijome), Center of Physics (Optometry), School of Sciences, University of Minho, Braga, Portugal.

Supported in part by grants from the Ministerio de Ciencia e Innovación Research (SAF2008-01114 and SAF2009-13342) (Dr. Montés-Micó) and Fundação para a Ciência e Tecnologia of Portugal (FCT-SFRH-BD-34303-2007) (Dr. Fernandes).

Corresponding author: José F. Alfonso, MD, PhD, Instituto Oftalmológico Fernández-Vega, Avenida Doctores Fernández-Vega 114, 33012, Oviedo, Spain. E-mail: j.alfonso@fernandez-vega.com. image analysis. ${ }^{24,25}$ A minimum of 100 cells was required in each image to process the cell counting.

\section{Phakic Intraocular Lens Size and Power Calculation}

The Visian Implantable Collamer Lens pIOL for myopia is rectangular and $7.0 \mathrm{~mm}$ wide. It is available in 4 overall lengths $(11.5 \mathrm{~mm}, 12.0 \mathrm{~mm}, 12.5 \mathrm{~mm}, 13.0 \mathrm{~mm})$ and a dioptric power range of -3.00 to -23.00 diopters (D). In all cases, a model ICL V4 pIOL was implanted and the target was emmetropia (when possible). The pIOL size was determined based on the horizontal white-to-white (WTW) distance and ACD, measured with the Orbscan II device following the manufacturer's recommendations; that is, the size was calculated by adding $0.5 \mathrm{~mm}$ to the horizontal WTW measurement. Power calculation for the pIOL was performed using the modified vertex formula in the power-table software provided by the manufacturer. The pIOL implantation technique has been described. ${ }^{26,27}$

\section{Follow-up}

Postoperative follow-up visits were at 1 day; 1 week; 1,3 , and 6 months; and 1 year and then yearly thereafter. Uncorrected distance visual acuity (UDVA), CDVA, slitlamp examination, refraction, ECD, fundus examination, and intraocular pressure (IOP) were performed at each visit. For averaging, visual acuities were converted to $\log$ MAR values; then, the means and standard deviations (SDs) were back-calculated to Snellen acuity. The central separation between the anterior surface of the crystalline lens and the posterior surface of the pIOL (vault) was first assessed using an optical section during routine slitlamp examination. Vault was classified in 5 levels by comparing the separation between the anterior surface of the crystalline lens and the posterior surface of the pIOL with the central corneal thickness (CCT). ${ }^{26} \mathrm{~A}$ few years after the first pIOLs were implanted, vault was also assessed using optical coherence tomography (OCT) (Visante, Carl Zeiss Meditec AG). In this method, the vault was measured perpendicular to the lens apex or at the narrowest space between both surfaces. The percentage of ECD loss was determined as follows: endothelial cell loss $(\%)=$ (preoperative ECD - postoperative $\mathrm{ECD}) /$ preoperative ECD.

\section{Statistical Analysis}

Data analysis was performed using SPSS for Windows software (version 16.01, SPSS, Inc.). Normality of data was checked by the Kolmogorov-Smirnov test and analyzed using the paired $t$ test, Wilcoxon rank-sum test, or analysis of variance with multiple comparisons, where appropriate, to determine statistical differences for refractive, visual, and adverse outcomes. Differences were considered statistically significant when the $P$ value was less than 0.05 .

\section{RESULTS}

This study cohort comprised 188 eyes of 111 patients, of which $80(72 \%)$ were women. Table 1 shows the preoperative demographic data of the patients and the pIOL characteristics. 


\begin{tabular}{|c|c|c|}
\hline Parameter & Mean \pm SD & Range \\
\hline Age (y) & $33.5 \pm 6.1$ & 24,45 \\
\hline \multicolumn{3}{|l|}{ Manifest refraction (D) } \\
\hline Sphere & $-10.76 \pm 3.39$ & $-20.00,-1.50$ \\
\hline Cylinder & $-0.97 \pm 0.84$ & $-3.50,0.00$ \\
\hline \multicolumn{3}{|l|}{ Keratometry (D) } \\
\hline Steep & $44.50 \pm 1.57$ & $40.50,47.25$ \\
\hline Flat & $43.50 \pm 1.23$ & $40.00,47.00$ \\
\hline ECD (cells $\left./ \mathrm{mm}^{2}\right)$ & $2695 \pm 467$ & 2005,4103 \\
\hline $\mathrm{ACD}(\mathrm{mm})$ & $3.16 \pm 0.25$ & $2.84,3.80$ \\
\hline $\mathrm{CCT}(\mu \mathrm{m})$ & $521 \pm 40$ & 473,636 \\
\hline WTW distance (mm) & $11.72 \pm 0.35$ & $11.10,13.00$ \\
\hline \multicolumn{3}{|l|}{ Phakic IOL } \\
\hline Sphere (D) & $-14.78 \pm 3.80$ & $-22.50,-2.50$ \\
\hline Size $(\mathrm{mm})$ & $12.2 \pm 0.4$ & $11.5,13.0$ \\
\hline \multicolumn{3}{|l|}{ Pupil (mm) } \\
\hline Scotopic & $6.4 \pm 0.7$ & $4.5,7.0$ \\
\hline Photopic & $5.0 \pm 0.9$ & $2.0,6.0$ \\
\hline
\end{tabular}

\section{Stability and Predictability of Manifest Refraction}

Figure 1 shows the improvement in and stability of the mean spherical equivalent (SE) over time. The mean SE decreased from $-11.17 \pm 3.40 \mathrm{D}$ preoperatively to $-0.23 \pm 0.50 \mathrm{D} 1$ month postoperatively (95\% confidence interval $[\mathrm{CI}],-0.15$ to -0.02 ) and $-0.88 \pm 0.72 \mathrm{D}$ at 5 years $(95 \% \mathrm{CI},-0.68$ to -1.09 ). The mean change in SE throughout the follow-up was

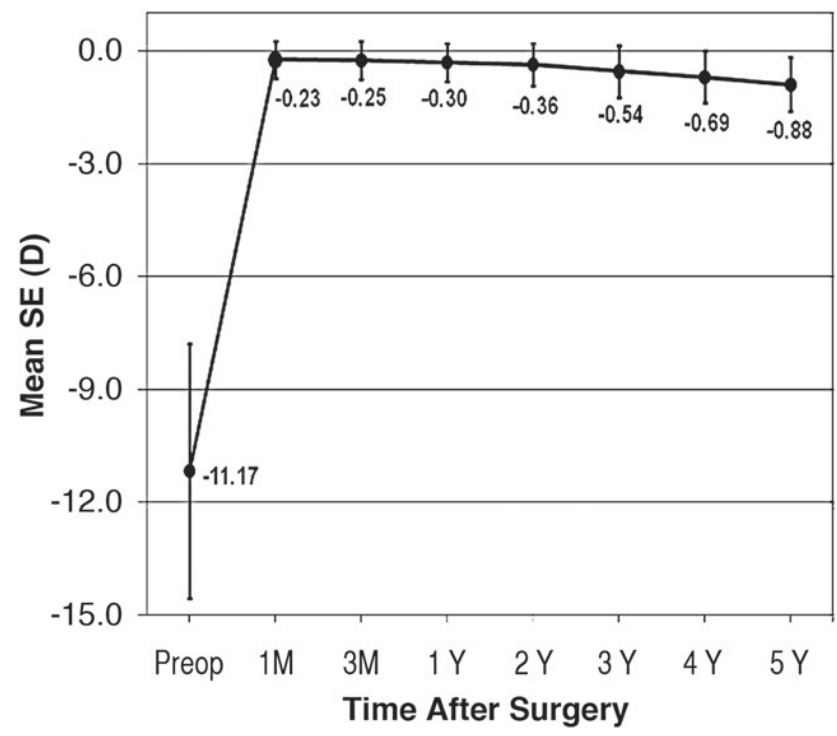

Figure 1. Time course (stability) of the SE after pIOL implantation $(\mathrm{SE}=$ spherical equivalent $)$.
$-0.65 \pm 0.65 \mathrm{D}(P<.001$, Wilcoxon signed-rank test $)$. High levels of predictability were achieved early after surgery; 163 eyes $(86.7 \%)$ were within $\pm 0.50 \mathrm{D}$ and 182 eyes $(96.8 \%)$ were within $\pm 1.00 \mathrm{D}$ of the attempted correction at the 1-month visit. The improvement was maintained over the postoperative follow-up $\left(r^{2}=\right.$ .953 at 5 years; Figure 2). Five years postoperatively, 19 eyes $(38.0 \%)$ were within $\pm 0.50 \mathrm{D}$ and 31 eyes $(62.0 \%)$ were within $\pm 1.00 \mathrm{D}$ of SE; 16 eyes $(32.0 \%)$ and 3 eyes $(6.0 \%)$ were undercorrected by more than $1.00 \mathrm{D}$ and by more than $2.00 \mathrm{D}$, respectively (Figure 3 ).

\section{Visual Acuity, Safety, and Efficacy}

Uncorrected Distance Visual Acuity Figure 4 shows the cumulative Snellen acuity over time. The preoperative Snellen UDVA was 20/400 or worse in 176 eyes (93.6\%). One month after pIOL implantation, the mean Snellen decimal UDVA was $0.77 \pm 0.22(95 \%$ $\mathrm{CI}, 0.74$ to 0.80$)$; it was $0.71 \pm 0.25$ (95\% CI, 0.67 to $0.74)$ and $0.69 \pm 0.26(95 \% \mathrm{CI}, 0.64$ to 0.71$)$ at 4 years and 5 years, respectively. At every follow-up visit, all eyes had a UDVA of 20/80 or better, with more than $30 \%$ achieving a UDVA of $20 / 20$ or better.

Corrected Distance Visual Acuity The mean preoperative CDVA was $0.74 \pm 0.21$ Snellen lines. All eyes had $20 / 80$ or better CDVA postoperatively. At 5 years, the mean Snellen decimal CDVA was $0.83 \pm$ 0.15 ( $95 \%$ CI, 0.79 to 0.87 ). The safety index (postoperative CDVA/preoperative CDVA) was $1.19 \pm 0.27$ and $1.27 \pm 0.33$ at 1 month and 5 years, respectively; 35 of 50 eyes $(70.0 \%)$ had a CDVA of $20 / 25$ or better at 5 years. The proportion of eyes with $20 / 20$ or better UDVA at 5 years (34.0\%) was greater than the proportion having a preoperative CDVA of 1.0 or better $(23.9 \%)$. The overall efficacy index (ratio of

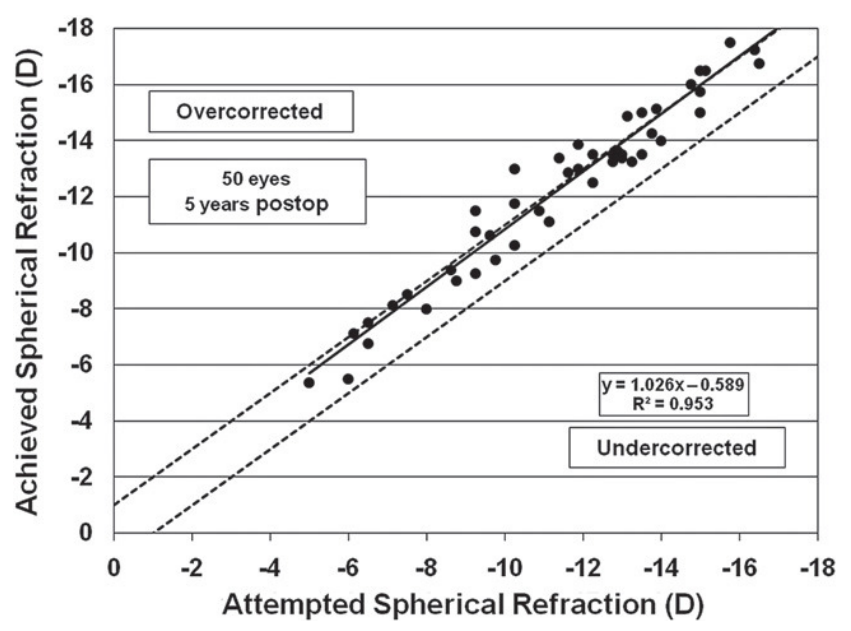

Figure 2. Predictability of mean SE (attempted versus achieved) 5 years after pIOL implantation. 


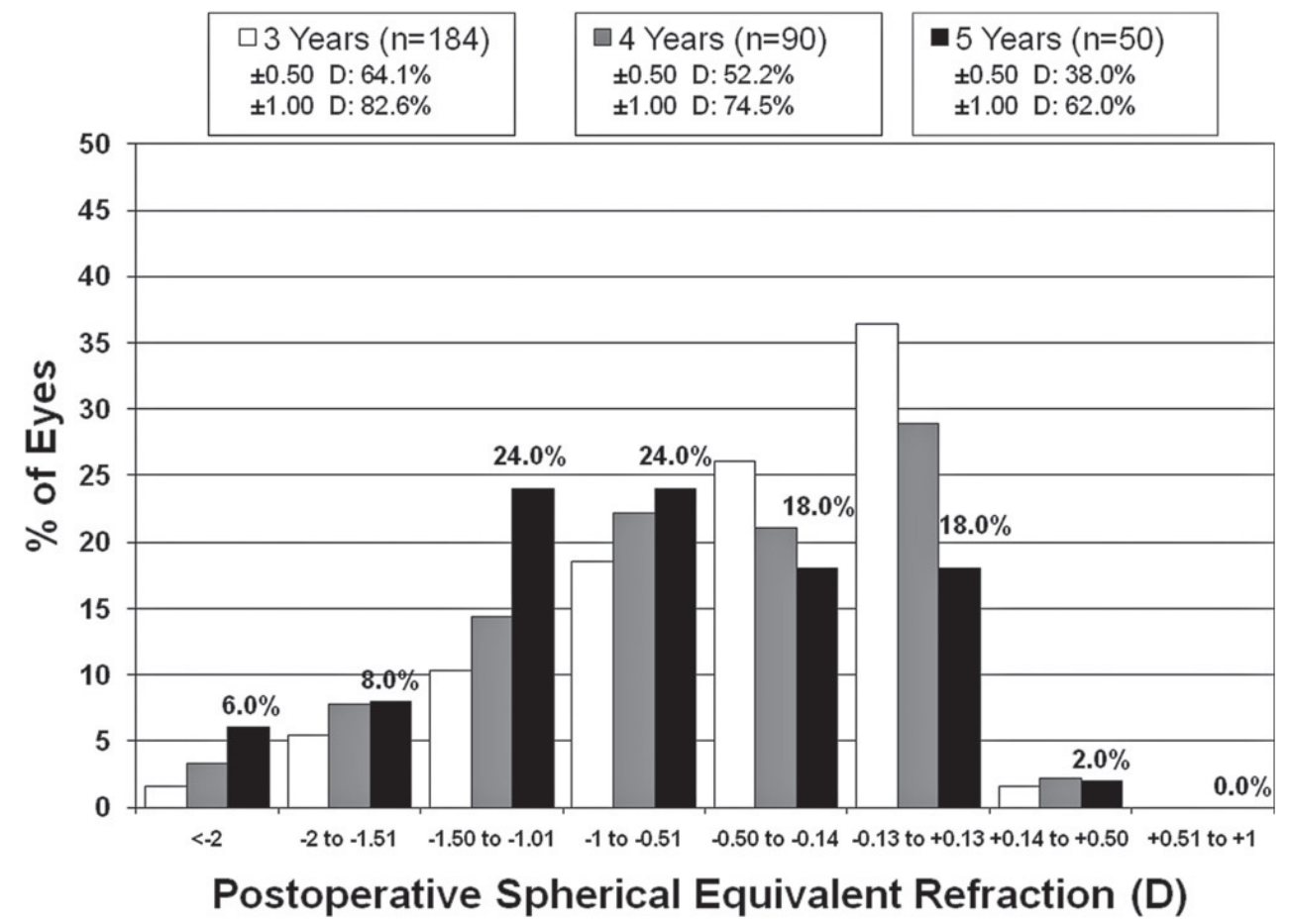

Figure 3. Spherical equivalent refractive accuracy at 3 years, 4 years, and 5 years.

postoperative UDVA/preoperative CDVA) was 0.89 \pm 0.35 at 5 years. The CDVA was stable over time, with no eye losing more than 2 lines. At 5 years, 5 eyes (10.0\%) had no change in CDVA, 19 (38.0\%) gained 1 line, $24(48.0 \%)$ gained 2 lines or more, $1(2.0 \%)$ lost 1 line, and 1 lost 2 lines (Figure 5).

\section{Endothelial Cell Density, Intraocular Pressure, and Vault}

The mean ECD decreased from $2698 \pm 467$ cells $/ \mathrm{mm}^{2}$ preoperatively to $2495 \pm 357$ cells $/ \mathrm{mm}^{2} 5$ years postoperatively, representing a mean endothelial cell loss of $7.5 \%$. When this loss was considered cumulatively at

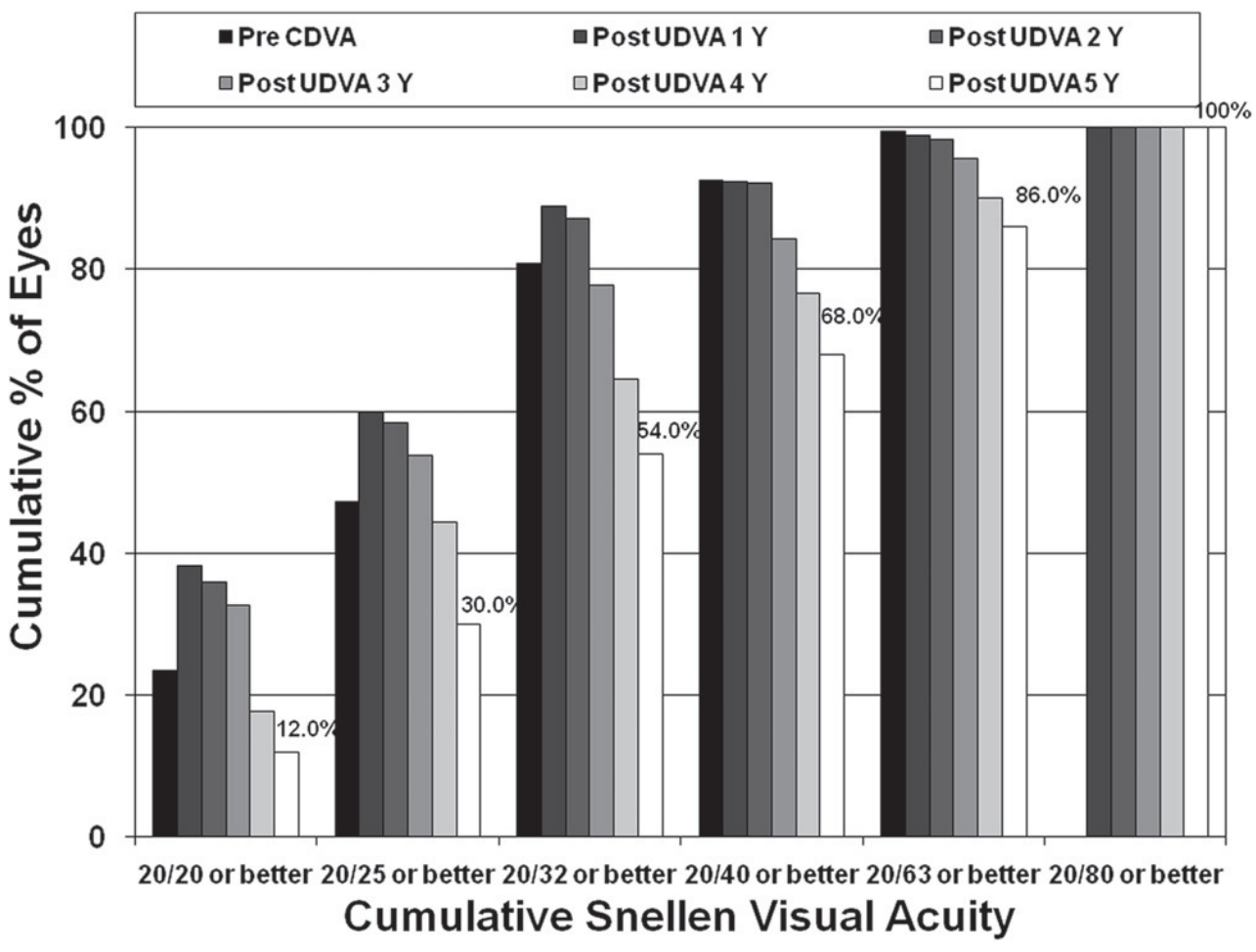

Figure 4. Efficacy bar chart showing postoperative UDVA results in the context of preoperative CDVA (CDVA = corrected distance visual acuity; UDVA = uncorrected distance visual acuity). 


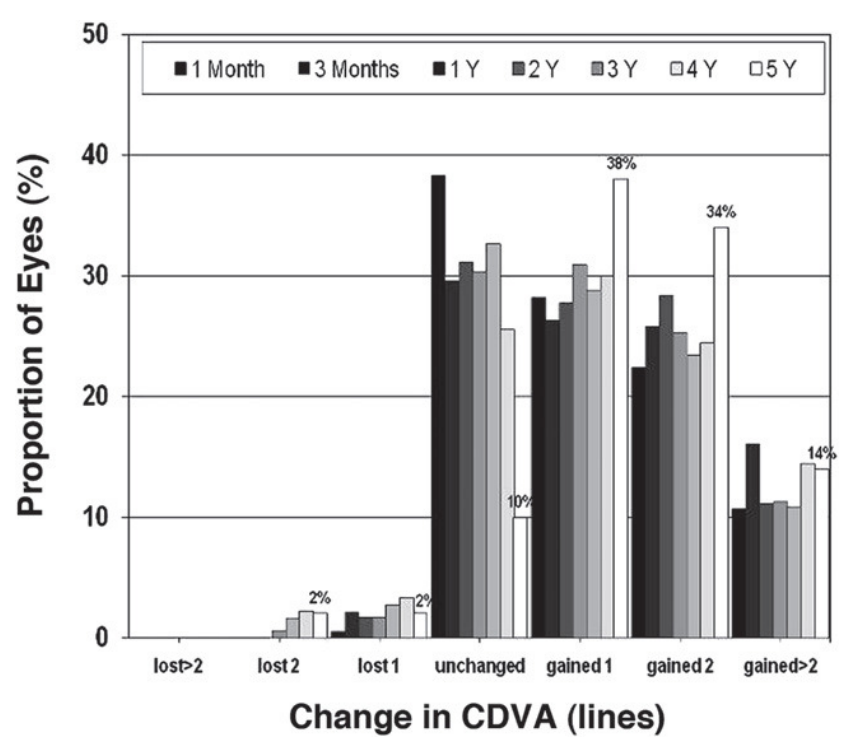

Figure 5. Changes in CDVA (safety) over the follow-up $(\mathrm{CDVA}=$ corrected distance visual acuity).

consecutive intervals through 5 years, the total 5-year loss was $7.7 \%$ (Figure 6).

The mean IOP was $13.9 \pm 1.8 \mathrm{~mm} \mathrm{Hg}$ preoperatively and $13.8 \pm 1.5 \mathrm{~mm} \mathrm{Hg} 5$ years postoperatively. There were no statistically significant differences in mean IOP between visits $(P>.05$, paired sample $t$ test).

The mean postoperative vault assessed at the slitlamp was $2.4 \pm 1.0$ at 1 month and $2.0 \pm 0.7$ at 5 years. The mean vault measured with OCT was 410 $\pm 228 \mu \mathrm{m}$ (95\% CI, 361 to 459$), 354 \pm 166 \mu \mathrm{m}$ (95\%

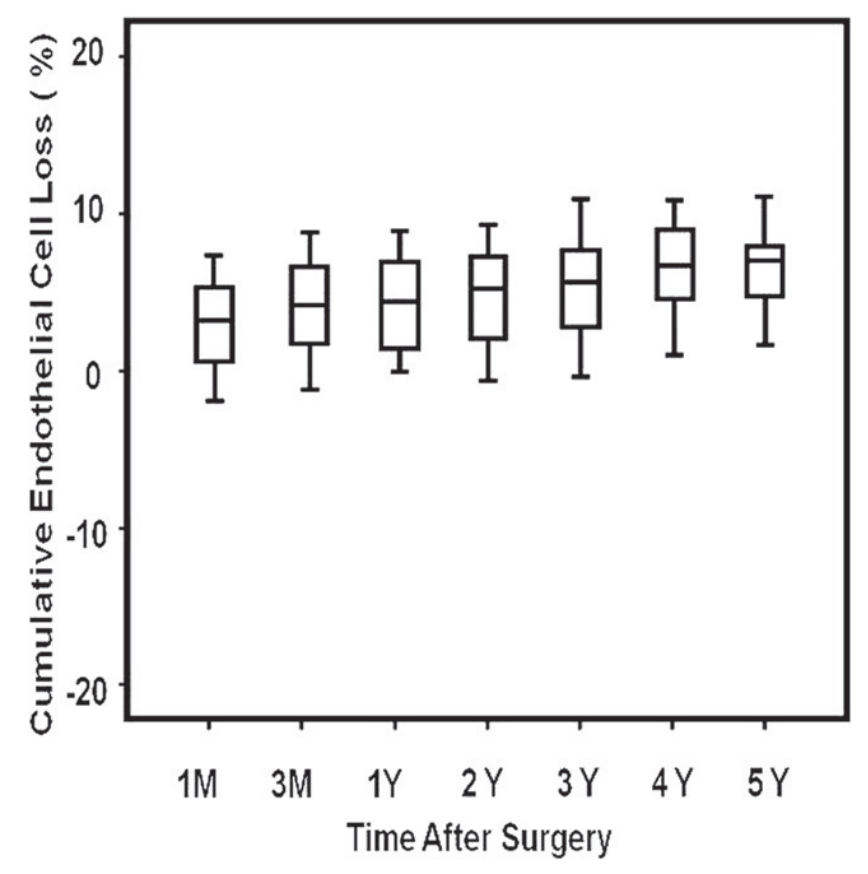

Figure 6. Cumulative cell loss after pIOL implantation.
CI, 296 to 412), and $364 \pm 198 \mu \mathrm{m} \mathrm{(95 \%} \mathrm{CI,} 294$ to 434 ) at 3 years, 4 years, and 5 years, respectively; there were no statistically significant differences in the mean vault between follow-up visits $(P=.325$, ANOVA).

\section{Adverse Events and Secondary Surgery}

There were no intraoperative complications, and no eye required pIOL explantation or repositioning. One eye developed a clinically significant symptomatic anterior subcapsular cataract 35.7 months after pIOL implantation. The 40-year-old patient had a preoperative SE of $-13.50 \mathrm{D}$ and a CDVA of 20/40; 1 month after pIOL implantation, theSE was $+0.25 \mathrm{D}$ and the UDVA was 20/32. Three years after surgery, the eye lost 2 lines of CDVA and the vault was $180 \mu \mathrm{m}$. Simultaneous phacoemulsification, pIOL extraction, and Acri.Smart 366 IOL (Acri.Tech $\mathrm{GmbH}$ ) implantation was successfully performed. After cataract surgery, the UDVA was $20 / 40$, the CDVA was 20/32, and the SE was -0.75 D.

Two eyes developed an asymptomatic anterior subcapsular cataract 27.4 and 55.2 months, respectively, after pIOL implantation. Both eyes lost 1 line of CDVA over the preoperative value but had 20/25 CDVA at the last follow-up visit. Although neither eye required cataract surgery, the patients were scheduled for closer follow-up.

No pigmentary glaucoma, pupillary block, or other vision-threatening complications occurred at any time during the follow-up; however, 3 eyes had a mild transient increase in IOP (up to $27 \mathrm{~mm} \mathrm{Hg}$ ) during the first 3 months.

\section{DISCUSSION}

Most studies of pIOL implantation report short-term clinical outcomes (up to 1 or 2 years), and few have spanned 3 or more years to allow observation of the long-term clinical and refractive results. ${ }^{1,22,23}$ In the present study, we confirmed the very good results in all measures of safety, efficacy, predictability, and stability of Visian Implantable Collamer Lens pIOL implantation to correct moderate to high myopia throughout a 5-year follow-up. The outcomes were consistent between patients and between follow-up visits, with most eyes maintaining or improving CDVA and no eye losing more than 2 lines. The safety index was higher than 1.18 at all postoperative visits. There was also an improvement in UDVA; more than $30 \%$ of eyes achieved a UDVA of $20 / 20$ or better at all follow-up visits, and the mean change in SE between visits was approximately $0.65 \mathrm{D}$ up to 5 years.

Clinical results with the earlier version of the pIOL we evaluated in this study confirm that the implantation procedure is a feasible treatment option for 
various ranges of ametropia and that it gives excellent visual and refractive results, even if some complications occurred. ${ }^{20,28-30}$ In addition, when compared with the visual outcomes of laser keratorefractive procedures, pIOL implantation seems to provide better visual performance with equal or better efficacy and safety. ${ }^{31-35}$ In a 3-year FDA myopic Implantable Collamer Lens study of 526 eyes of 294 patients, ${ }^{1} 94.7 \%$ of patients had a UDVA of $20 / 40$ or better, $67.5 \%$ were within $\pm 0.50 \mathrm{D}$ of the predicted refraction, and $88.2 \%$ were within $\pm 1.00 \mathrm{D}$ of the predicted refraction. The mean improvement in CDVA was between 0.5 lines and 0.6 lines. Three eyes $(0.8 \%)$ had a decrease in CDVA of 2 lines, 15 eyes (2.9\%) required an additional refractive procedure, 14 eyes $(2.7 \%)$ developed early asymptomatic anterior subcapsular cataract, and 3 eyes $(0.6 \%)$ required pIOL removal with cataract extraction and IOL implantation.

Lackner et al., 22 in a 3-year follow-up study of 76 eyes (mean SE $-16.5 \pm 5.6$; range -5.5 to $-33.4 \mathrm{D}$ ) found an improvement in UDVA from $0.04 \pm 0.04$ preoperatively to $0.35 \pm 0.28$ Snellen lines at the last patient visit; the mean postoperative refraction was $0.4 \mathrm{D}$ (range 0.0 to $2.2 \mathrm{D}$ ). In that study, 11 eyes $(14.5 \%)$ developed lens opacification that was significantly progressive in 5 eyes, probably as a result of surgical trauma and older age.

In a study by Kamiya et al. ${ }^{23}$ of 56 eyes of 34 patients (mean SE $-9.8 \pm 3.0 \mathrm{D}$; range -4.00 to $-15.25 \mathrm{D}$ ), the mean UDVA and CDVA improved from $1.49 \pm 0.22$ $\log$ MAR and $-0.15 \pm 0.08 \log$ MAR, respectively, preoperatively to $-0.03 \pm 0.23$ and $-0.21 \pm 0.09$, respectively, 4 years after surgery. Five eyes (9\%) lost 1 line of CDVA; no eye lost 2 or more lines. Fortyfour eyes $(79 \%)$ were within $\pm 0.50 \mathrm{D}$ of the attempted correction, and 52 eyes $(93 \%)$ were within $\pm 1.00 \mathrm{D}$. The mean percentage of endothelial cell loss was $3.7 \% 4$ years after surgery.

The results in the present study are comparable to those previously reported. In our study, $70.0 \%(35 / 50)$ of eyes achieved a CDVA of 20/25 or better 5 years after surgery. The greatest loss of CDVA was 2 lines in 1 eye that developed a clinically significant symptomatic anterior subcapsular cataract. Regarding refractive outcomes, a smaller proportion of eyes in this study than in previous studies were within $\pm 0.50 \mathrm{D}$ and $\pm 1.00 \mathrm{D}$ of the attempted correction; this is because $9.0 \%$ of eyes $(17 / 188)$ in our study had a preoperative SE higher than $-15.00 \mathrm{D}$ and $8.5 \%(16 / 188)$ had refractive cylinder of $2.00 \mathrm{D}$ or higher that could not be fully corrected by the strongest available pIOL power. These cases were targeted for undercorrection. However, the correlation between the attempted refraction and the achieved refraction was high, with $82.6 \%(152 / 184)$ of eyes and $62.0 \%(31 / 50)$ of eyes being within $\pm 1.00 \mathrm{D}$ of the desired refraction at 3 years and 5 years, respectively. The SE was also stable throughout the followup, with a slight tendency toward a myopic shift. The shift might be explained by the biometric changes that occur in myopic patients ${ }^{36}$ or by the decrease in vault, ${ }^{27}$ narrowing the gap between the pIOL and the crystalline lens and increasing the effective power of the optical system.

The most significant concern about pIOL implantation is cataract formation. In the Implantable Collamer Lens FDA trial, ${ }^{1}$ the rate of cataract formation was $2.1 \%$. Other studies report a secondary cataract formation rate between $1.6 \%{ }^{37}$ and $14.5 \% .{ }^{22}$ In a 5-year follow-up study by Sanders, ${ }^{21}$ anterior subcapsular opacities occurred in $5.9 \%$ of 526 eyes, with $1.3 \%$ progressing to clinically significant cataract; progression to clinically significant cataract generally occurred in patients with very high myopia or in older patients. In a study by Alfonso et al. ${ }^{27}$ of 964 myopic eyes of 531 patients, anterior subcapsular cataract developed in 13 eyes $(1.3 \%)$; the cataract developed before 1 year in 2 eyes, between 2 years and 3 years in 7 eyes, and after 3 years in 4 eyes, indicating that patient age and lower vault are the most important factors in pIOL-induced cataract. In a recent metaanalysis by Chen et al. $^{38}$ of 6338 eyes that included anglesupported, iris-supported, and posterior chamber pIOLs, the incidence of cataract formation in eyes with the Implantable Collamer Lens pIOL (1933 eyes; 218 V2 or earlier models, 249 V3 models, 877 V4 models, and 589 design not specified) was $8.48 \%$. Early cataract formation was related to surgical trauma and late cataract formation, to pIOL-crystalline lens contact.

In the present study, 3 eyes $(1.6 \%)$ developed late anterior subcapsular cataract. The cataract was clinically significant in 1 case, leading to pIOL removal and phacoemulsification with IOL implantation. This eye was highly myopic $(-13.50 \mathrm{D})$ and had a vault of $180 \mu \mathrm{m} 3$ years after surgery. In the other 2 eyes with anterior subcapsular cataract, the loss of CDVA was 1 Snellen line and there was no need for a second surgery, although the patients were scheduled for closer follow-up. The main theories of the cause of late anterior subcapsular cataract development are absent or lower vault and the tendency of the vault to decrease slightly over time, causing constant or intermittent pIOL-crystalline lens contact. ${ }^{27,39,40} \mathrm{~A}$ limitation of our study was that it was not possible to measure vault objectively with OCT from the first day after pIOL implantation; thus, we could not objectively measure the changes in vault over time. However, the mean vault assessed at the slitlamp and compared with CCT decreased slightly over time (mean vault level $2.4 \pm 1.0$ at 1 month and $2.0 \pm 0.7$ 
at 5 years), which was confirmed with OCT (mean vault $410 \pm 228 \mu \mathrm{m}$ at 3 years and $364 \pm 198 \mu \mathrm{m}$ at 5 years).

Another limitation of our study is the small number of patients who completed the 5-year follow-up. Most patients were lost to follow-up between the 4-year and 5 -year visits, with 184 eyes (97.9\%) available for the 3 -year visit. This is usual with successful treatments such as pIOL implantation because patients who are satisfied with the outcomes often do not return for the recommended regular visits. Although this may have had some impact on the final results, a higher follow-up rate would likely improve the results in areas such as efficacy, predictability, safety, and vault. A significant decrease in vault can cause changes in visual acuity and in the worst cases, cataract formation. Thus, we believe that a better follow-up rate would have improved our results. Although our results match well with those in previous studies with a similar sample size, this limitation does have some implications. For example, the trend toward regression in myopia over time (mean $0.88 \mathrm{D}$ at 5 years) might be because more patients with regression than patients who had no change in refraction attended the follow-up visits.

Endothelial cell loss is another concern with pIOL implantation. The rate of postoperative endothelial cell loss has been reported to be approximately $6.5 \%$ at 2 years $^{28}$ and $6.09 \%$ at 3 years. ${ }^{41}$ Others report a mean endothelial cell loss of $3.7 \%$ at 4 years. $^{23}$ In the FDA clinical study, Edelhauser et al. ${ }^{17}$ found a cumulative endothelial cell loss between $8.4 \%$ and $8.9 \%$ over the first 3 years and between $8.4 \%$ and $9.5 \%$ over the first 4 years, with an endothelial cell loss rate of $2 \%$ to $3 \%$ per year over the first 3 years of follow-up. There was a $0.1 \%$ increase in cells between 3 years and 4 years, suggesting that endothelial remodeling and stability may have been achieved by 3 years. We found a mean endothelial cell loss of approximately $1.5 \%$ per year and a mean cumulative endothelial cell loss of $7.7 \%$ at 5 years. The ongoing cell loss was more noticeable during the first year (5.5\%), after which it decreased and stabilized. The percentage of ECD loss with age is reported to be 0.5 to 0.6 per year. $^{42,43}$ Thus, our results may be explained by corneal remodeling after the surgical procedure rather than by continuing cell loss due to the effect of aging.

Another important concern after pIOL implantation is increased IOP, which in most cases is associated with significant angle narrowing by forward iris displacement ${ }^{44}$ or with chronic pigment dispersion. ${ }^{18}$ In the present study, 3 eyes $(1.6 \%)$ had a mild transient increase in IOP (up to $27 \mathrm{~mm} \mathrm{Hg}$ ); the eyes had between 15.00 D and 17.00 D of preoperative myopia and had high initial pIOL vault; none of those eyes needed a second surgical procedure or prolonged topical medication.
In summary, our long-term results suggest that Visian Implantable Collamer Lens pIOL implantation to correct moderate to high myopia is a safe and effective procedure that provides predictable and stable refractive results over the long term; in this case, over 5 years. The rates of postoperative complications were low, and there were no vision-threatening complications throughout the follow-up. Future studies with a longer follow-up are necessary to assess lateonset complications, specifically in the development of anterior lens opacities and the change in vault over time.

\section{REFERENCES}

1. ICL in Treatment of Myopia (ITM) Study Group. United States Food and Drug Administration clinical trial of the Implantable Collamer Lens (ICL) for moderate to high myopia; three-year follow-up. Ophthalmology 2004; 111:1683-1692

2. Zaldivar R, Davidorf JM, Oscherow S. Posterior chamber phakic intraocular lens for myopia of -8 to -19 diopters. J Refract Surg 1998; 14:294-305

3. Uusitalo RJ, Aine E, Sen NH, Laatikainen L. Implantable contact lens for high myopia. J Cataract Refract Surg 2002; 28:29-36

4. Gonvers M, Othenin-Girard P, Bornet C, Sickenberg M. Implantable contact lens for moderate to high myopia: short-term followup of 2 models. J Cataract Refract Surg 2001; 27:380-388

5. Arne JL, Lesueur LC. Phakic posterior chamber lenses for high myopia: functional and anatomical outcomes. J Cataract Refract Surg 2000; 26:369-374

6. Pesando PM, Ghiringhello MP, Di Meglio G, Fanton G. Posterior chamber phakic intraocular lens (ICL) for hyperopia: ten-year follow-up. J Cataract Refract Surg 2007; 33:1579-1584

7. Davidorf JM, Zaldivar R, Oscherow S. Posterior chamber phakic intraocular lens for hyperopia of +4 to +11 diopters. J Refract Surg 1998; 14:306-311

8. Alfonso JF, Baamonde B, Madrid-Costa D, Fernandes P, Jorge J, Montés-Micó R. Collagen copolymer toric posterior chamber phakic intraocular lenses to correct high myopic astigmatism. J Cataract Refract Surg 2010; 36:1349-1357

9. Alfonso JF, Fernández-Vega L, Fernandes P, GonzálezMéijome JM, Montés-Micó R. Collagen copolymer toric posterior chamber phakic intraocular lens for myopic astigmatism; oneyear follow-up. J Cataract Refract Surg 2010; 36:568-576

10. Sanders DR, Schneider D, Martin R, Brown D, Dulaney D, Vukich J, Slade S, Schallhorn S. Toric Implantable Collamer Lens for moderate to high myopic astigmatism. Ophthalmology 2007; 114:54-61

11. Alfonso JF, Palacios A, Montés Micó R. Myopic phakic STAAR collamer posterior chamber intraocular lenses for keratoconus. J Refract Surg 2008; 24:867-874

12. Alfonso JF, Lisa C, Abdelhamid A, Montés-Micó R, PooLópez A, Ferrer-Blasco T. Posterior chamber phakic intraocular lenses after penetrating keratoplasty. J Cataract Refract Surg 2009; 35:1166-1173

13. Alfonso JF, Fernández-Vega L, Lisa C, Fernandes P, GonzálezMéijome JM, Montés-Micó R. Collagen copolymer toric posterior chamber phakic intraocular lens in eyes with keratoconus. J Cataract Refract Surg 2010; 36:906-916

14. Kamiya K, Shimizu K, Hikita F, Komatsu M. Posterior chamber toric phakic intraocular lens implantation for high myopic astigmatism in eyes with pellucid marginal degeneration. J Cataract Refract Surg 2010; 36:164-166 
15. Allan BD, Argeles-Sabate I, Mamalis N. Endophthalmitis rates after implantation of the intraocular Collamer lens: survey of users between 1998 and 2006. J Cataract Refract Surg 2009; 35:766-769

16. Dejaco-Ruhswurm I, Scholz U, Pieh S, Hanselmayer G, Lackner B, Italon C, Ploner M, Skorpik C. Long-term endothelial changes in phakic eyes with posterior chamber intraocular lenses. J Cataract Refract Surg 2002; 28:1589-1593

17. Edelhauser HF, Sanders DR, Azar R, Lamielle HICL in Treatment of Myopia Study Group. Corneal endothelial assessment after ICL implantation. J Cataract Refract Surg 2004; 30:576-583

18. Chun YS, Park IK, Lee HI, Lee JH, Kim JC. Iris and trabecular meshwork pigment changes after posterior chamber phakic intraocular lens implantation. J Cataract Refract Surg 2006; 32:1452-1458

19. Bylsma SS, Zalta AH, Foley E, Osher RH. Phakic posterior chamber intraocular lens pupillary block. J Cataract Refract Surg 2002; 28:2222-2228

20. Smallman DS, Probst L, Rafuse PE. Pupillary block glaucoma secondary to posterior chamber phakic intraocular lens implantation for high myopia. J Cataract Refract Surg 2004; 30:905-907

21. Sanders DR. Anterior subcapsular opacities and cataracts 5 years after surgery in the Visian Implantable Collamer Lens FDA trial. J Refract Surg 2008; 24:566-570

22. Lackner B, Pieh S, Schmidinger G, Simader C, Franz C, DejacoRuhswurm I, Skorpik C. Long-term results of implantation of phakic posterior chamber intraocular lenses. J Cataract Refract Surg 2004; 30:2269-2276

23. Kamiya K, Shimizu K, Igarashi A, Hikita F, Komatsu M. Fouryear follow-up of posterior chamber phakic intraocular lens implantation for moderate to high myopia. Arch Ophthalmol 2009; 127:845-850. Available at: http://archopht.ama-assn. org/cgi/reprint/127/7/845.pdf. Accessed December 5, 2010

24. de Sanctis U, Machetta F, Razzano L, Dalmasso P, Grignolo FM. Corneal endothelium evaluation with 2 noncontact specular microscopes and their semiautomated methods of analysis. Cornea 2006; 25:501-506

25. González-Méijome JM, Jorge J, Queirós A, Peixoto-deMatos SC, Parafita MA. Two single descriptors of endothelial polymegethism and pleomorphism. Graefes Arch Clin Exp Ophthalmol 2010; 248:1159-1166. Available at: http://www.springerlink.com/content/u1064375617363p3/fulltext.pdf. Accessed December 5, 2010

26. Alfonso JF, Lisa C, Palacios A, Fernandes P, GonzálezMéijome JM, Montés-Micó R. Objective vs subjective vault measurement after myopic implantable collamer lens implantation. Am J Ophthalmol 2009; 147:978-983

27. Alfonso JF, Lisa C, Abdelhamid A, Fernandes P, Jorge J, Montés-Micó R. Three-year follow-up of subjective vault following myopic implantable collamer lens implantation. Graefes Arch Clin Exp Ophthalmol 2010; 248:1827-1835. Available at: http:// www.springerlink.com/content/I5m6t26622q316t4/fulltext.pdf. Accessed December 5, 2010

28. Jiménez-Alfaro I, Benítez del Castillo JM, García-Feijoó J, Gil de Bernabé JG, Serrano de la Iglesia JM. Safety of posterior chamber phakic intraocular lenses for the correction of high myopia: anterior segment changes after posterior chamber phakic intraocular lens implantation. Ophthalmology 2001; 108:90-99; discussion by SM MacRae, 99

29. ICL in Treatment of Myopia (ITM) Study Group. Postoperative inflammation after implantation of the implantable contact lens. Ophthalmology 2003; 110:2335-2341

30. Sarikkola A-U, Sen HN, Uusitalo RJ, Laatikainen L. Traumatic cataract and other adverse events with the implantable contact lens. J Cataract Refract Surg 2005; 31:511-524
31. Igarashi A, Kamiya K, Shimizu K, Komatsu M. Visual performance after implantable collamer lens implantation and wavefront-guided laser in situ keratomileusis for high myopia. Am J Ophthalmol 2009; 148:164-170

32. Kamiya K, Shimizu K, Igarashi A, Komatsu M. Comparison of Collamer toric contact lens implantation and wavefrontguided laser in situ keratomileusis for high myopic astigmatism. J Cataract Refract Surg 2008; 34:1687-1693; erratum, 2011

33. Sanders D, Vukich JA. Comparison of implantable collamer lens (ICL) and laser-assisted in situ keratomileusis (LASIK) for low myopia. Cornea 2006; 25:1139-1146

34. Schallhorn S, Tanzer D, Sanders DR, Sanders ML. Randomized prospective comparison of Visian Toric Implantable Collamer Lens and conventional photorefractive keratectomy for moderate to high myopic astigmatism. J Refract Surg 2007; 23: 853-867

35. Sanders DR, Vukich JA. Comparison of implantable contact lens and laser assisted in situ keratomileusis for moderate to high myopia. Cornea 2003; 22:324-331

36. Jorge J, Almeida JB, Parafita MA. Refractive, biometric and topographic changes among Portuguese university science students: a 3-year longitudinal study. Ophthalmic Physiol Opt 2007; 27:287-294

37. Chang JS, Meau AY. Visian Collamer phakic intraocular lens in high myopic Asian eyes. J Refract Surg 2007; 23:17-25

38. Chen L-J, Chang Y-J, Kuo JC, Rajagopal R, Azar DT. Metaanalysis of cataract development after phakic intraocular lens surgery. J Cataract Refract Surg 2008; 34:1181-1200

39. Kamiya K, Shimizu K, Kawamorita T. Changes in vaulting and the effect on refraction after phakic posterior chamber intraocular lens implantation. J Cataract Refract Surg 2009; 35:15821586

40. Schmidinger G, Lackner B, Pieh S, Skorpik C. Long-term changes in posterior chamber phakic intraocular Collamer lens vaulting in myopic patients. Ophthalmology 2010; 117: 1506-1511

41. Pineda-Fernández A, Jaramillo J, Vargas J, Jaramillo $M$, Jaramillo J, Galíndez A. Phakic posterior chamber intraocular lens for high myopia. J Cataract Refract Surg 2004; 30: 2277-2283

42. Niederer RL, Perumal D, Sherwin T, McGhee CNJ. Age-related differences in the normal human cornea: a laser scanning in vivo confocal microscopy study. Br J Ophthalmol 2007; 91:11651169. Available at: http://www.ncbi.nlm.nih.gov/pmc/articles/ PMC1954900/pdf/1165.pdf. Accessed December 5, 2010

43. Bourne WM, Nelson LR, Hodge DO. Central corneal endothelial cell changes over a ten-year period. Invest Ophthalmol Vis Sci 1997; 38:779-782. Available at: http://www.iovs.org/content/ 38/3/779.full.pdf. Accessed December 5, 2010

44. Chung T-Y, Park SC, Lee MO, Ahn K, Chung E-S. Changes in iridocorneal angle structure and trabecular pigmentation with STAAR Implantable Collamer Lens during 2 years. J Refract Surg 2009; 25:251-258

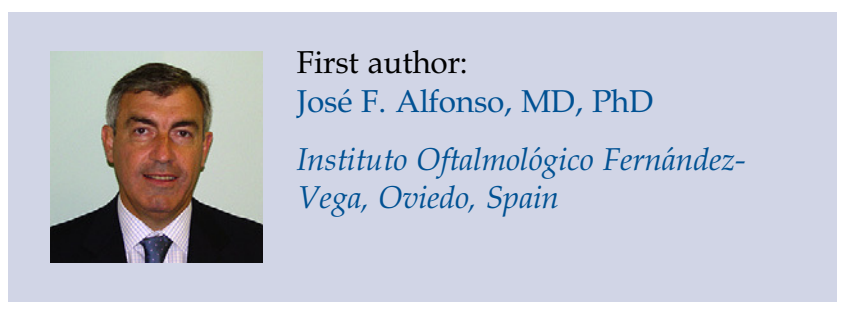

